\title{
Shopping Motivation in Live Streaming: A Means- End Chain Approach
}

\author{
Earth Chandrruangphen ${ }^{1}$, Nuttapol Assarut ${ }^{2,}$ " and Sukree Sinthupinyo ${ }^{3}$ \\ ${ }^{1}$ Technopreneurship and Innovation Management Program, Graduate School, Chulalongkorn University, \\ Bangkok, Thailand \\ ${ }^{2}$ Department of Marketing, Chulalongkorn Business School, Chulalongkorn University, Bangkok, Thailand \\ ${ }^{3}$ Department of Computer Engineering, Chulalongkorn University, Bangkok, Thailand
}

\begin{abstract}
.
Facebook (FB) is a social networking site that offers live streaming feature, FB Live, where some users use it as a means to demonstrate and sell fashion clothes while some may watch and make purchase. Prior studies suggest that several shopping attributes may influence consumer values including product attributes (e.g. assortment, quality, trendiness, and brand name), seller attributes (e.g. presentation, interactivity, guidance, image, physical attractiveness, and humor), and price. However, it is not known if such list of attributes is fully applicable or complete. Therefore, there is a need to investigate the hierarchical nature of shopping motivation in live streaming. This study intends to explore live streaming shopping attributes and develop consumer value hierarchy by adopting means-end chain theory. A total of 30 in-depths interviews with FB Live users who shop fashion clothes in Thailand were conducted using laddering technique. The results are shown in hierarchical value maps identifying several attributes that motivate users to shop and their corresponding consumer values. Several important attributes are found in addition to the known list including clothing style, clear presentation of price, seller politeness, seller verbal attractiveness, seller pacing, background ambiance, broadcast timing announcement, number of viewers, seller FB page, and fast delivery. Three major motivational patterns have emerged from the maps including frictionless shopping, shopping enjoyment, and value seeking. Three minor ones have also emerged including quality seeking, fashion orientation, and product selection support. They are presented along with associated attributes allowing fashion clothing sellers to correspond.
\end{abstract}

Keywords: fashion shopping; laddering technique; online shopping; shopping value; social commerce

\section{Introduction}

The technological advancements in online shopping have shaped how customers behave from the moments they are motivated to shop through to the moments of purchase (Shankar, Inman, Mantrala, Kelley, \& Rizley, 2011). Live streaming feature is a recent technology in online shopping that enables sellers to directly communicate and engage with shoppers through live product demonstrations, product promotional activities and gaming, and real-time shopping guidance (Cai, Wohn, Mittal, \& Sureshbabu, 2018; Sun, Shao, Li, Guo, \& Nie, 2019). 
In fashion cloth shopping, live streamers can demonstrate how clothing items are worn and give guidance on the fabric quality or the occasion to wear. On Facebook (FB), shoppers can use live streaming feature called FB Live to ask questions, confirm purchase, or interact with the streamers via text chat (Wongkitrungrueng \& Assarut, 2018; Wongkitrungrueng, Dehouche, \& Assarut, 2020).

The study of shopping motivations is an important topic that helps managers and retail business organizations develop market segmentations and marketing strategies (McGoldrick, 2002). Several prior studies have studied shopping attributes that affect consumer preferences in live streaming shopping (Wongkitrungrueng \& Assarut, 2018; Leeraphong \& Sukrat, 2018; Cai et al., 2018; Sun et al., 2019). Some of these attributes include product attributes (e.g. assortment, quality, trendiness, and brand name), seller attributes (e.g. presentation, interactivity, guidance, image, physical attractiveness, and humor), pricing (cheap price and good price), and promotion. However, it is not known if such list of attributes is fully applicable or complete in the context of live streaming shopping. There is a need to investigate the hierarchical nature of shopping motivation.

Therefore, the research question is "What are the live stream attributes that motivate users to engage in fashion cloth shopping in FB live streaming?" The study aims to gain insights into the live stream attributes that influence shoppers to watch and purchase fashion clothes in live streaming and to develop consumer value hierarchy by adopting means-end chain theory.

The outcome of this study shall help live streaming sellers to better strategize and cater to the needs of the consumers based on the relevant live streaming attributes. And it will also be used to guide the development of the questionnaires for the future quantitative study. The ultimate goal in future research would be to apply insights from both studies into developing a tool that helps shoppers evaluate the live streams and get live stream recommendations.

\section{Literature Review}

\subsection{Live Streaming Shopping Motivation: Uses and Gratification Theory (UGT)}

According to UGT, people are motivated to participate in certain media because they receive gratification that it brings. In live streaming shopping, most literature examine utilitarian and hedonic motivations (Cai et al., 2018; Hou, Guan, Li, \& Chong, 2019; Leeraphong \& Sukrat, 2018). Utilitarian motivations help shoppers complete their shopping tasks while hedonic motivations represent shopping enjoyment. Cai et al. (2018) defines utilitarian motivations in terms of convenience, time saving, or cost saving. Their study also defines hedonic motivations in terms of fun, playfulness, and positive experience. Additionally, Wongkitrungrueng \& Assarut (2018) has also examined symbolic motivations which enhance shoppers' personal identity. Wongkitrungrueng et al. (2020) summarizes that several factors enhance consumers' experience and trust toward the seller which in turn motivate them to watch and make purchase in live streaming. Factors are related to product information, communication quality, enjoyment, and social presence. 


\subsection{Live Streaming Shopping Attributes}

Similar to how traditional store attributes motivate shopper to visit the physical store and how online shopping website attributes motivate shopper to visit the website, live stream attributes motivate shoppers to watch and shop from live stream. Though live stream attributes are different from those of traditional store and online shopping website, there are a lot of common attributes. Johnson, Kim, Mun, \& Lee (2015) has proposed eight store attributes that influence traditional store shopper satisfaction: product, service, location, facility, design, atmosphere, price, and leisure. Chen, Hsu, \& Lin (2010) presents a list of eight online shopping website attributes in three areas as follow: security, privacy, and usability as technology factors; convenience, trust, and delivery as shopping factors; and product value and merchandising as product factors. Other online shopping website attributes from other studies are as follow: brand image and online store image (Aghekyan-Simonian, Forsythe, Suk Kwon, \& Chattaraman, 2012); product assortment, product quality, price transparency, and website convenience (Davari, Iyer, \& Rokonuzzaman, 2016).

In live streaming shopping, prior studies have proposed several live stream attributes that influence customer shopping behaviors. Wongkitrungrueng \& Assarutt (2018) shows seller characteristics have influence on customer trust and Engagement. Cai et al. (2018) studies how seller physical attractiveness and seller interactivity can motivate shopping. Hou et al. (2019) studies how factors such as seller interactivity, seller humor, and seller sex appeal influence live streaming viewers. Sun et al. (2019) shows that seller's abilities to show products to customers, to directly respond to customer questions, and to personally help guide customers in shopping have positive influence on shopping engagement and purchase intention.

\subsection{Means-End Chains (MEC) Theory}

MEC is based on the laddering interview technique that describes an interviewing process and its analysis. In this technique, the product users are asked about the product attributes and why they are important so that there would be linkages between the attributes and the consumer values. Reynold and Gutman (1988) describes the technique in detail. Information from the interviews is extracted to form ladders where each ladder begins with a product attribute and followed with a sequence of functional consequences, psychosocial consequences, and consumer values. Functional consequences refer to the qualities of the live stream that shoppers anticipate immediately when engaging with the live stream, while psychosocial consequences refer to the states of emotions and social outcomes experienced by the shoppers (Wagner, 2017). The analysis would result in an implication matrix and in hierarchical value map (HVM). An implication matrix contains the frequency of the linkages between two elements in the sequence appearing in the interviews. The resulting HVM shows a depiction of implication matrix and can be used for interpretation. As a method to explore and analyze shopping motivations, Wagner (2007) has used the qualitative MEC to study consumer shopping behaviors in traditional shopping malls. In that study, attributes related to personnel, products, pricing, and store are identified. The consequences of those attributes in HVM are then used identify four dominant motivational patterns. These patterns allow retailers to better correspond to the consumer values based on the shopping attributes that drive those values. 


\section{Research Methodology}

The qualitative method is used in this study to identify the live stream attributes impacting trust and customer intentions to watch and shop fashion clothes in FB Live in Thailand. FB Live is chosen as a platform to collect live streaming shopping data because, according to Electronic Transactions Development Agency (2020), 64\% of the online sellers in Thailand indicate FB as their selling platform and $47.5 \%$ of the online shoppers indicate it as their shopping platform.

Interviewees in this study consisted of $30 \mathrm{FB}$ Live streaming shoppers in Thailand. The sample size of 20 to 25 people is recommended for this type of qualitative research and very few new insights are found beyond this point (Borgardt, 2020). To reach the interviewees, an advertisement was posted using FB ads which allowed FB users to sign up. Applicants were screened with a question to ensure that they have watched or made fashion clothing purchase through FB live streaming in the past 12 months. Thirty individuals were chosen from the pool of applicants that cover varying genders, age groups, and average spending per clothing item. To encourage participation in the interview, each interviewee received an incentive of 300 Thai Baht at the end of the interview. The in-depth interviews were conducted over the telephone and each lasted approximately thirty minutes to one hour.

Each laddering interview is intended to solicit a list of relevant shopping attributes which would become a starting point in the laddering procedure. At the beginning of the interview, an interviewee was asked "What are the top four most important characteristics that a live stream should have to motivate users to watch and buy fashion clothes in live streams?" For each attribute that the interviewee mentioned, a series of "why is this important to you?" questions was asked. The answers from the interviewee would form a ladder up until the terminal value in the ladder was reached. In addition to the characteristics mentioned by the interviewee, a list of live streaming shopping attributes from the literature were also asked to see if interviewee would find any of them relevant and to gather insights into the values behind those attributes. Such attributes include product attributes (e.g. assortment, quality, trendiness, and brand name), seller attributes (e.g. presentation, interactivity, guidance, image, physical attractiveness, and humor), pricing (cheap price and good price), and promotion.

The composition of the interviewees was balanced with 15 males (50\%) and 15 females $(50 \%)$. Among females, the numbers of interviewees from age groups 20 to 25,26 to 35,36 and above were 5, 5, and 5 respectively. Among males, the numbers of interviewees from age groups 20 to 25, 26 to 35, 36 and above were 5, 8, and 2 respectively. Most interviewees spend an average of $250 \mathrm{THB}$ on a piece of cloth (33\%) followed by 750 THB (23\%).

In order to analyze the interviews, the coding for elements was performed on each interview segment that represented a ladder. Each element would correspond to one these levels: live streaming attributes, functional consequences, psychosocial consequences, and values. After the coding was completed, the online software tool LadderUX was used to aid the data analysis. The software generated an implication matrix where each entry indicated the number of times an element was directly or indirectly mentioned by the interviewee to be related to another element. A cut-off point of 3 was used as recommended by prior research (Borgardt, 2020; Wagner, 2007). That is, the number of associations (N) must be mentioned at least three times to be considered relevant and such association would appear on the hierarchical value map 
(HVM). The notation of association frequency shows direct association frequency to the left of the point and the indirect association frequency to the right. For example, an association of 19.5 between product assortment and finding the preferred product would indicate that there were 19 instances where interviewees mentioned that product assortment was important for them because it directly helped them find preferred products. And it would also indicate that there were 5 instances where interviewees mentioned some other elements in between these two elements. And also, for the sake of clarity and simplicity, HVM diagram would only show indirect links when there exist both direct and indirect links between the two elements.

\section{Results}

The formatting guidelines of the HVM diagrams, as shown in Fig. 1, are based on similar prior work (Wagner, 2007). Elements are differentiated based on their types (e.g. attributes, functional consequences, psychosocial consequences, and values) using grey scales. Elements that were mentioned more frequently appear in boxes with thicker borders. Lastly, relation links between elements that are associated more frequently appear in thicker arrows. The levels of thickness are formatted in three levels. Elements that were mentioned up to 9 times have weakest borders, 10 to 19 times have thicker borders, and 20 or more times have thickest borders. Relation links that are associated up to 4 times appear in weakest arrows, 5 to 9 times appear in thicker arrows, and 10 or more times appear in thickest arrows.

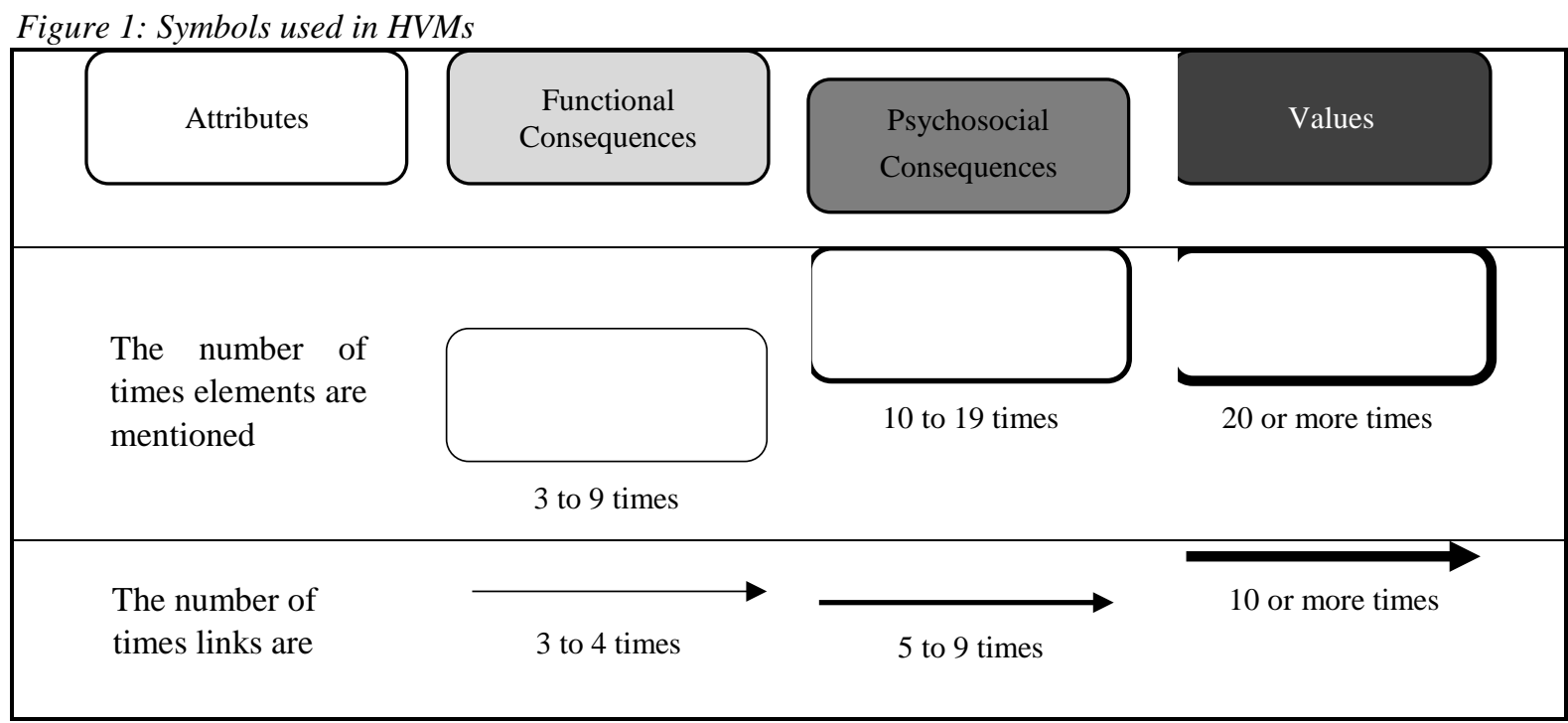

For the sake of clarity, this study displays the results in five separate HVM diagrams. The value $\mathrm{N}$ for each element denotes the number of times the element was mentioned by the interviewees. Fig. 2 shows HVM that is based on five product attributes: product assortment, product quality, product trendiness, product brand name, and product style. In this HVM diagram, four motivational patterns appear: frictionless shopping, fashion orientation, quality seeking, and value seeking. Frictionless shopping is defined as consumers' smooth experience of the shopping process (Wagner, 2007). This first motivational factor relies on the elements that can enable consumers to find the right products with ease. Interviewees of this pattern are 


\section{2nd International Conference on Research In MANAGEMENT}

motivated to shop from sellers who carry a large selection of clothes due to chances that several items would match their preferences and their time spent would be worthwhile. This motivational pattern subsumes functional consequence of seeing new interesting clothes and some of which could be fashionable as this factor also relies on the trendiness aspect of the product. Ladhari, Gonthier, \& Lajante (2019) defines fashion orientation as consumers' attraction to new fashion. This second motivational pattern relies solely on the trendiness aspect of the product where users find that watching live streaming helps them update fashion trends. Wagner (2007) defines quality seeking as consumers' preference towards quality of the product. Consumers with quality seeking motivational patterns mainly care about the quality of the product and are often times less price sensitive. For this third factor, the quality of clothes refers to the clothes being comfortable to wear and look beautiful when worn which boosts a person's self-confidence. Lastly, the fourth factor, the value seeking is defined as consumers' being satisfied with the good prices for the given quality. The prices do not have to be the absolute lowest prices, but they should be acceptable prices that consumers would feel that their money is well spent. Value seeking strongly relies on the products having good quality and also relies a little bit on product brand name. This is due to the facts that some interviewees believe that clothes with well-known brands tend to also be of good quality. Next, Fig. 3 shows HVM that is based on the attributes regarding good price, cheap price, clear price presentation, and promotion.

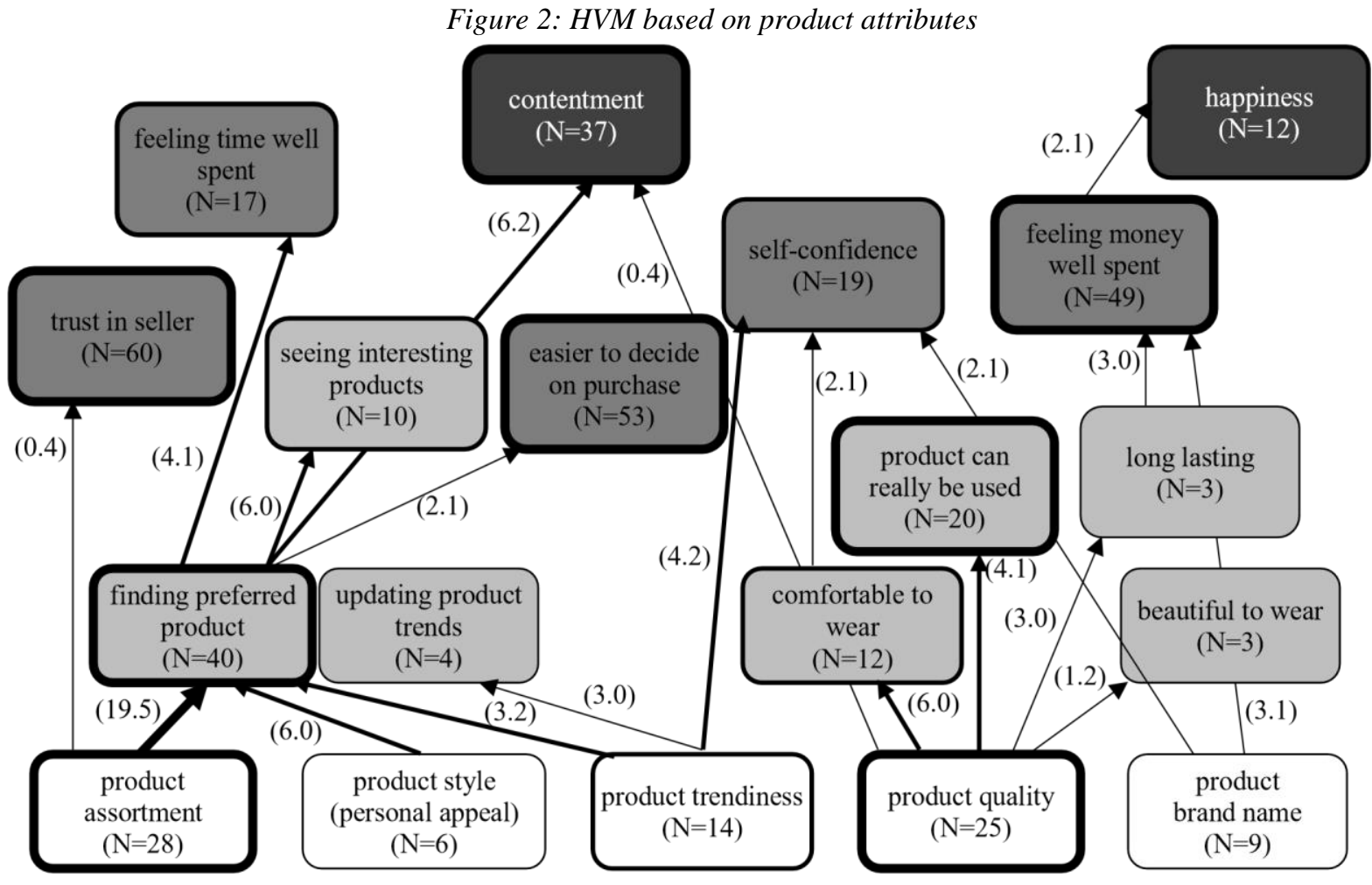




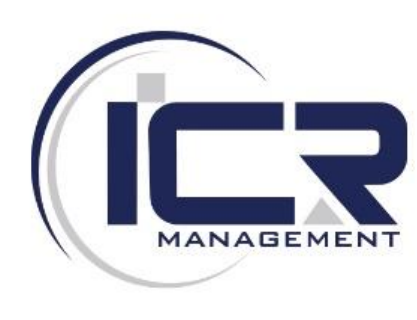

Figure 3: HVM based on price and promotion attributes

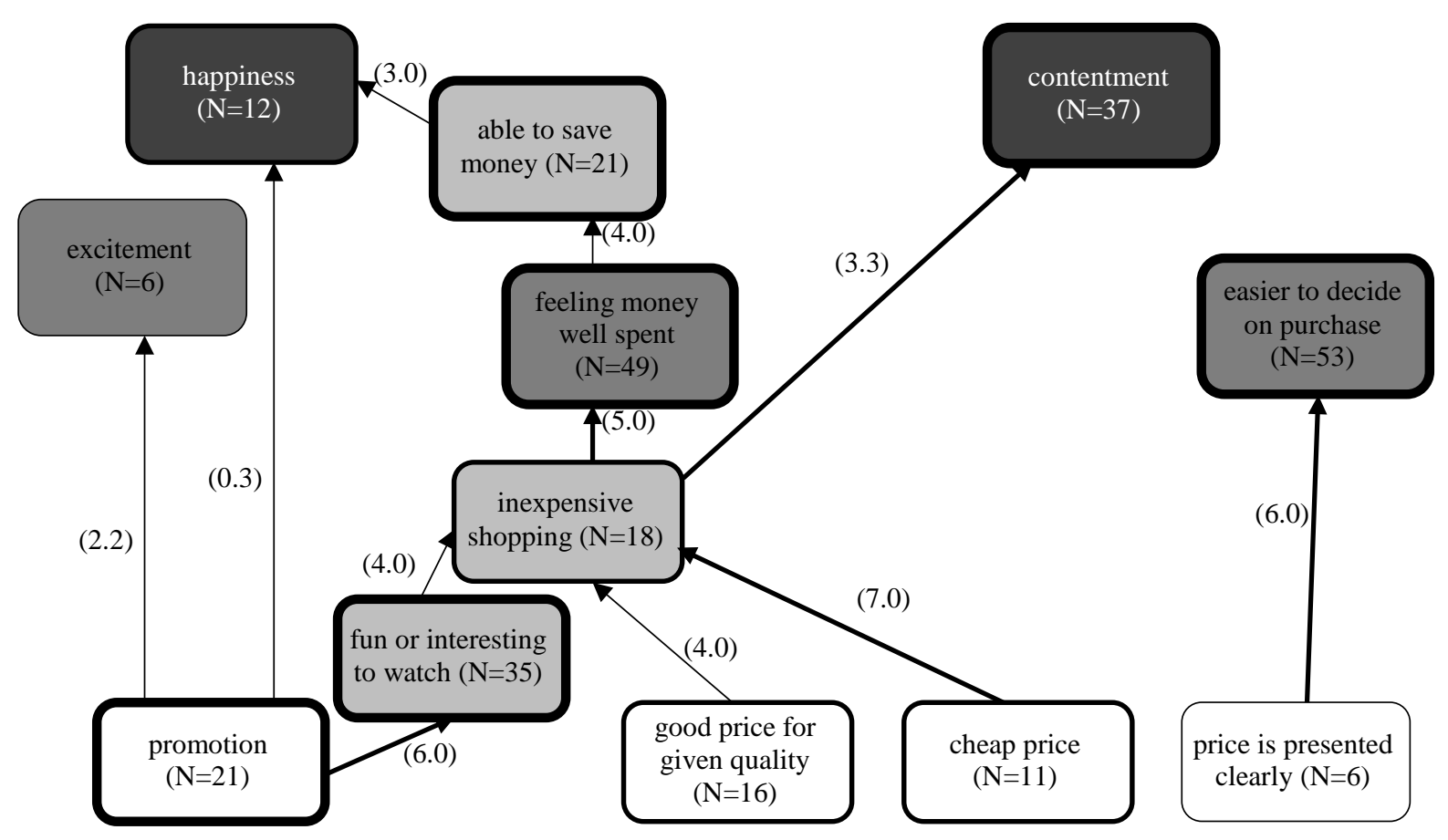

In this HVM diagram, two motivational patterns emerge: value seeking and shopping enjoyment. Firstly, consumers with value seeking mainly rely on price being either cheap or good given the quality. They focus on achieving best value for their money. By saving money, they feel that they have accomplished their shopping objectives and feel happy. Additionally, because they are mainly concerned with price, they also rely on the clear visibility of price. Several interviewees mentioned that they would like to know total price including all the delivery fees before confirming any purchase because they want to plan the order so as to minimize the fees. Secondly, shopping enjoyment is defined as consumers' enjoyment of shopping without the necessary plan to purchase (Ladhari et al., 2019). Shopping enjoyment provides for the emotional value of the shopping experience. In this case, interviewees find that promotional activities that involve competing against other shoppers to win free prizes or getting great discounts give them excitement and keep them engaged because it is fun. Shoppers who are motivated by enjoyment do not necessarily feel compelled to purchase anything, but they could do so if they happen to win the game. Next, Fig. 4 and Fig. 5 show two HVMs that are based on the attributes regarding sellers. Fig. 4 is based on seller presentation, seller interactivity, and seller guidance, while Fig. 5 is based on seller image, seller politeness, seller pacing, seller physical attractiveness, seller humor, and seller verbal attractiveness. 


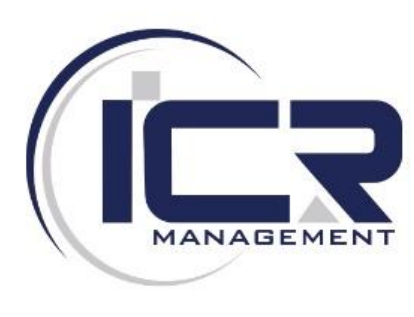

Figure 4: HVM based on seller presentation, seller interactivity, and seller guidance

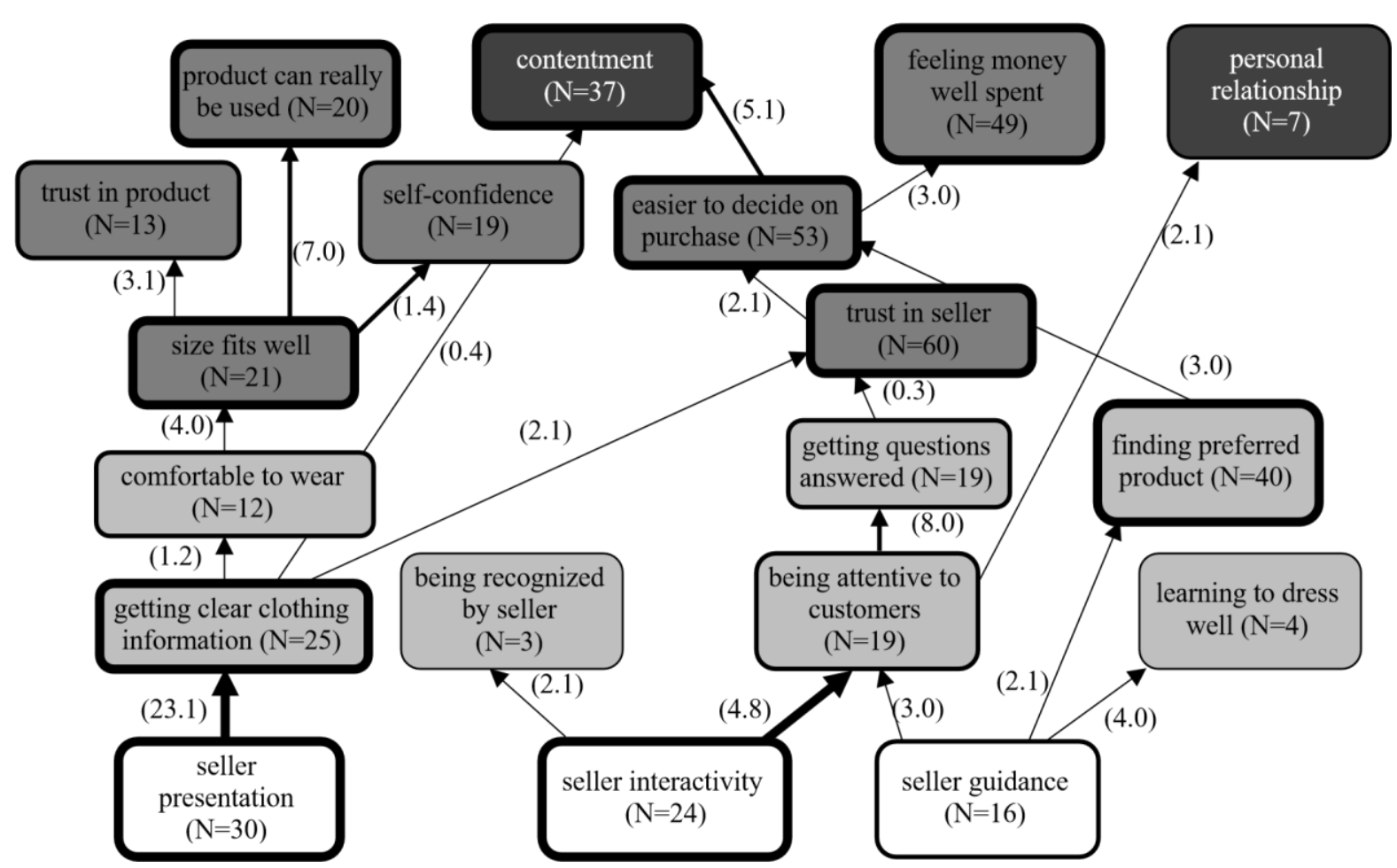

In HVM in Fig. 4, there seems to be one familiar motivational pattern and one new pattern appearing: frictionless shopping and product selection support. Frictionless shopping is characterized by the desire of shoppers to get clear information about the clothing in order to ensure that it can be worn comfortably, and the sizing is right. That is, shoppers are concerned with getting the right cloth that fits the body well and can really be worn. Essentially, this pattern heavily relies on the ability of seller to give clothing presentation. Moreover, consumers with frictionless shopping motivation have moderate desire to get answers from seller in order to have sufficient information to make purchase decision. Some interviewees indicated that they ask questions mostly to clarify the details of the clothing so they can decide to purchase. If they find that sellers do not pay attention to them, they may leave the live stream because they do not want to wait as it wastes their time. Sellers who are attentive to their comments and questions, sometimes earn their trust and they can make decision easier. As for the second motivational pattern, product selection support is defined as consumers' preference for choice making assistance (Sebald \& Jacob, 2019). Product selection support relies on the ability of seller to give shopping guidance that enables shoppers to learn how to dress well and to easier decide on which to purchase. It is important to note that the association of this motivational pattern is weak perhaps because the nature of live streaming caters to large group of audience and sellers are unable to provide significant shopping guidance to individual shoppers. Some interviewees mentioned that sellers usually share with them about the occasions to wear certain clothes and how different clothing pieces could be nicely matched together. These types of guidance help shoppers find the right clothing for themselves. 


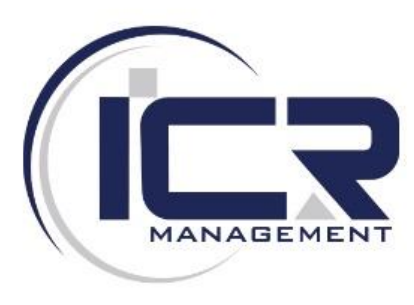

Figure 5: HVM based on the remaining seller attributes

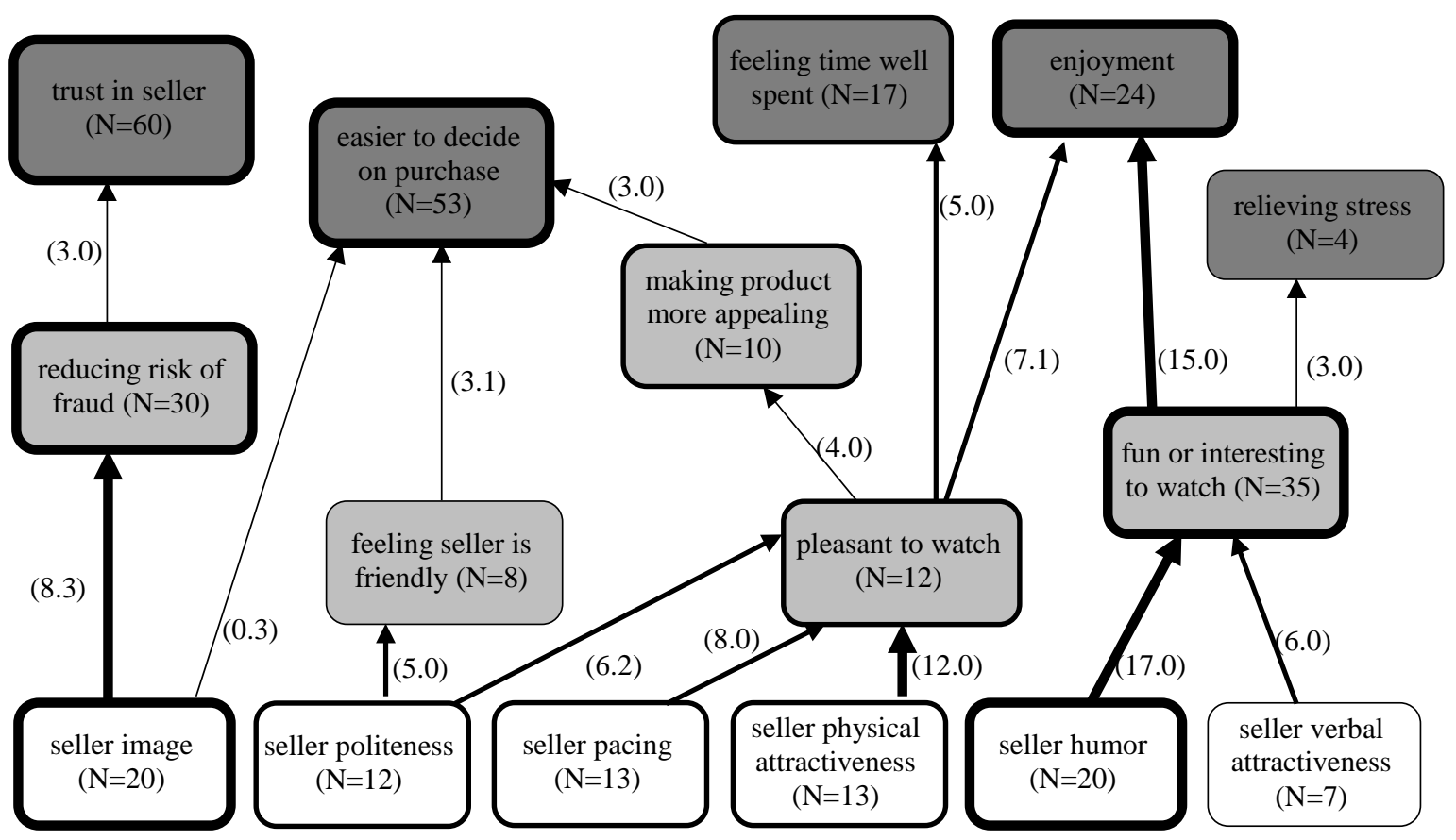

In HVM related to seller attributes in Fig. 5, both motivational patterns that emerge seem familiar: frictionless shopping and shopping enjoyment. In this cognitive map, frictionless shopping is characterized by being able to trust seller in terms of honesty and the ease of continuously watching the live stream. There is a strong association between seller image and the impact it has on fraud risk. Many interviewees mentioned that they tend to trust sellers whose image is clean and nothing bad has been said about them by other shoppers. They also mentioned that they would avoid buying from sellers with bad reputation. There are also several more moderate to strong associations between the ease of watching and three attributes namely seller politeness, seller pacing, and seller physical attractiveness. These links indicate that shoppers find sellers who are polite and good looking to be a welcoming sight. They also feel that sellers with these qualities make products look more appealing to buy. They also find that sellers should not stay on any particular item for too long as it becomes boring and difficult for them to stay watching. Sellers should move along to the subsequent products at reasonable pace. As for the third motivational pattern, shopping enjoyment has to do with experiencing fun, having a good time, and relieving stress. Seller humor has very strong association with making the live streaming experience fun and interesting to watch. Interviewees mentioned that they tend to stay engaged with sellers who have bright and colorful personalities or able to tell them interesting stories. It is important to note that, according the implication matrix, shoppers who are motivated by shopping enjoyment may also find sellers who are good looking to be an important attribute because there is a strong indirect linkage of (0.7) from physical attractiveness to enjoyment. The same cannot be said for the attributes of seller politeness and seller pacing because there is no indirect or direct linkages from them to enjoyment. Next, Fig. 6 shows the last HVM related to other remaining attributes. 


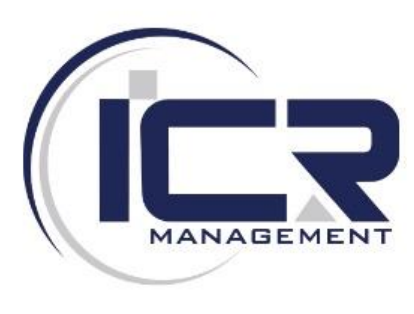

Figure 6: HVM based on other attributes

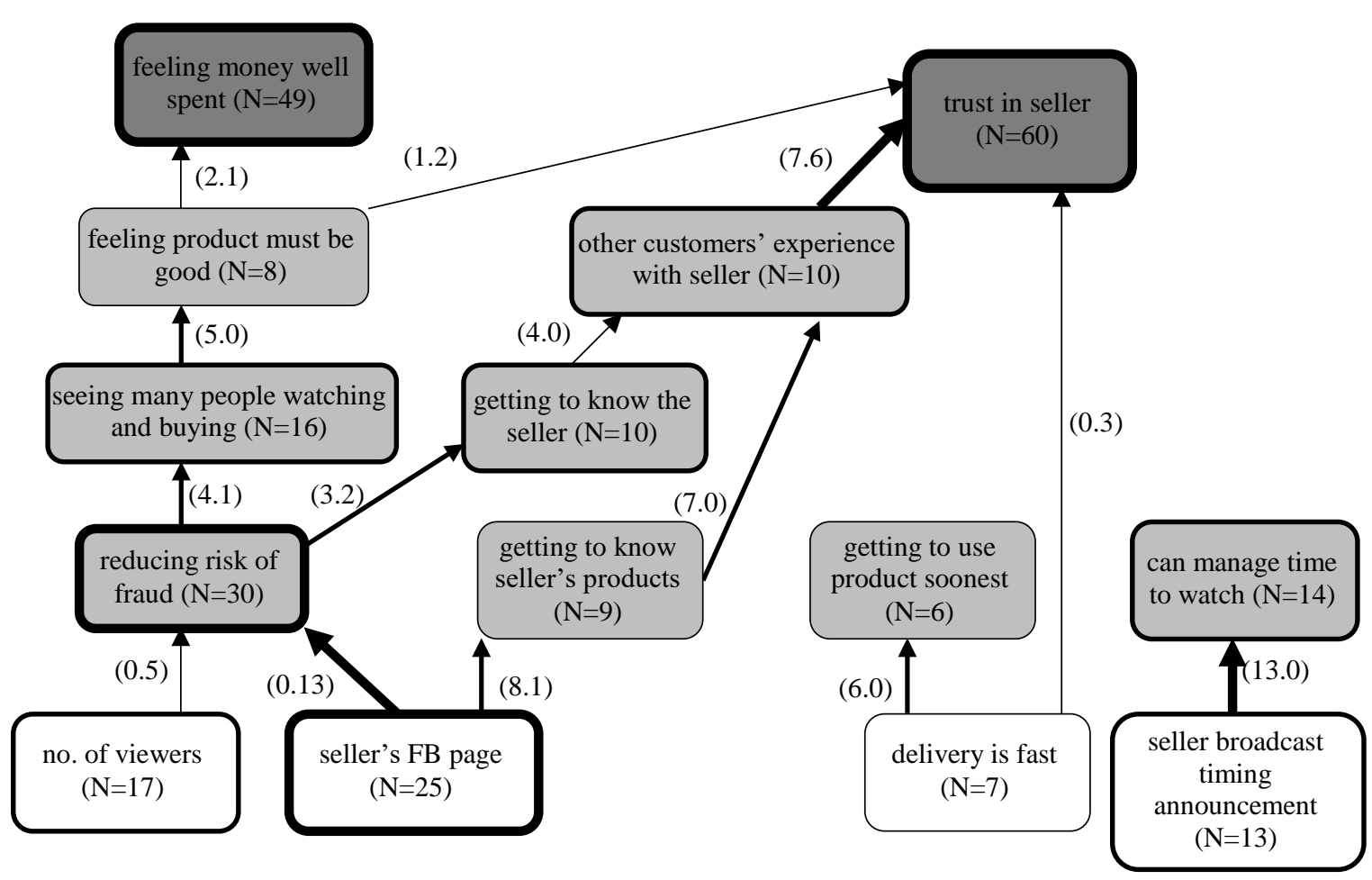

In the last HVM related to other attributes, a single motivational pattern emerges which is frictionless shopping. One of the key aspects of successful shopping is fraud risks reduction and being able to trust sellers to deliver what was promised. Trust, in general, is defined as the beliefs between parties based on different characteristics such as goodness, fairness, honesty, competence, predictability, benevolence, integrity, and many others (McKnight \& Chervany, 2001). Trust in seller is defined as the customer beliefs that the seller is competent and can be securely relied on to serve customer long-term interests (Crosby, Evans, \& Cowles, 1990). The indirect associations between trust in seller and two attributes namely the number of viewers and the content of sellers' FB page are strong. Interviewees mentioned that when they saw a large crowd gathered to watch a particular live stream, it made them feel that the product must be good, the price must be great, and the seller must be trustworthy even before knowing who the seller was, what clothing product was being sold, and at what price. In addition, interviewees mentioned that they investigated the content on sellers' FB page such as the comments other shoppers wrote about the sellers and how sellers responded to them, the evidence that there were recent orders being sent out for delivery, the recent product updates on the page, and even the physical location of the store if existed. All these contents allow shoppers to get to know who the seller is and to judge the sellers' trustworthiness. There is also a weak association between fast delivery to trust towards the seller which indicates that by delivering the order on time as expected, the shoppers may mildly increase their trust in seller. Lastly, it is worthwhile to also note the very strong association between seller broadcast timing announcement and the ability for shoppers to manage their time to watch the live stream. This meant that as part of the frictionless shopping, shoppers may need to manage their time to come 


\section{2nd International Conference on Research In MANAGEMENT}

watch the live stream. Quite a few interviewees mentioned that it is important for them to know the timing when sellers would broadcast their live stream at least half a day in advance so that they could clear their schedule to watch the live stream. Lastly, it is important to note that the background ambiance attribute has an indirect association of (0.2) with enjoyment, which has not met the cut-off point of 3 and therefore was not included in the HVM as relevant. However, unlike other attributes derived from the literature, background ambiance was a new finding and was not specifically asked to the interviewees. So, it is possible that background ambiance could be relevant to create shopping enjoyment if such attribute was specially asked to the interviewees.

By analyzing all of the HVMs, three major motivational patterns and three minor motivational patterns have emerged as shown in Fig. 7. The motivational patterns are considered major if they account for most of the associated links between attributes and their values. They are considered minor if they account for fewer associated links. Major motivational patterns include frictionless shopping, shopping enjoyment, and value seeking. While minor motivational patterns include quality seeking, fashion orientation, and product selection support.

Figure 7: Motivational Patterns

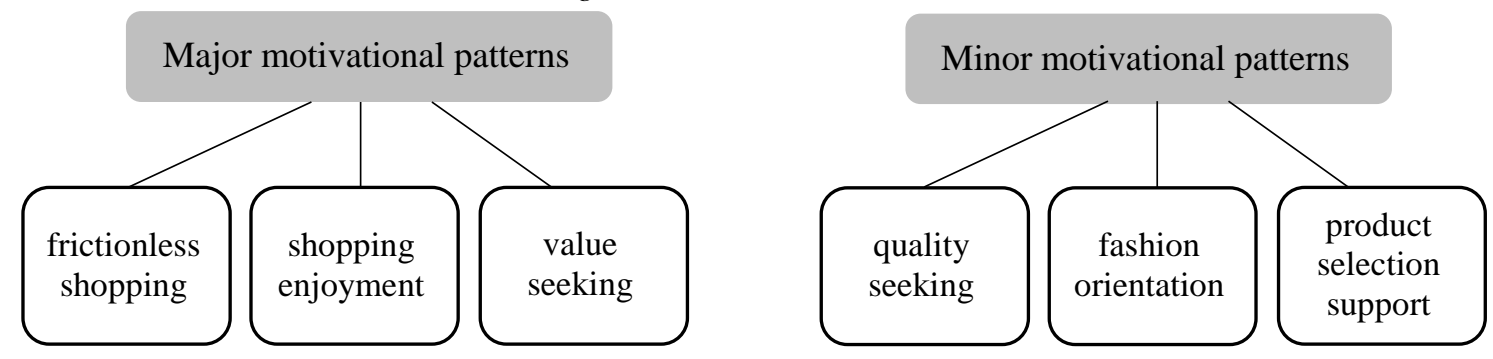

Sellers and retailers in live streaming can focus on each of these motivational patterns by addressing their associated attributes in order to deliver higher values for the customers:

- Frictionless shopping - product assortment, product style (personal appeal), product trendiness, seller presentation, seller interactivity, seller image, seller politeness, seller pacing, seller physical attractiveness, number of viewers, content on seller FB page, fast delivery, and seller broadcast timing announcement

- Shopping enjoyment - promotion, seller humor, seller verbal attractiveness, and seller physical attractiveness

- Value seeking - product quality, product brand name, good price for the given quality, cheap price, clear price presentation

- Quality seeking - product quality

- Fashion orientation - product trendiness

- Product selection support - seller guidance

\section{Discussion}

The prior studies in live streaming have suggested several shopping attributes to be relevant in motivating consumers to shop including product assortment, product quality, product trendiness, product brand name, seller presentation, seller interactivity, seller guidance, seller 
image, seller physical attractiveness, seller humor, cheap price, good price for the quality, and promotion. This study has investigated these shopping attributes and find that they are all still relevant in live streaming shopping for fashion clothing context. Moreover, this study has found a number of additional important attributes including product style (personal appeal), seller politeness, seller pacing, seller verbal attractiveness, clear price presentation, number of viewers, content on seller FB page, fast delivery, and seller broadcast timing announcement.

This study also finds new insights through the analysis of hierarchical theory of shopping motivation. Three major motivational patterns and three minor motivational patterns have been found along with their respective set of associated attributes. Sellers and retail managers can benefit from these findings by addressing the attributes of the live streams to achieve the desired improvements in the underlying motivational values. The HVMs can act as a tool to realize and understand shoppers' motivations that otherwise may not have been known.

\section{Conclusion}

The results of this study identify important shopping attributes that motivate consumers to watch and shop in live streaming. Moreover, the findings identify several motivational patterns that are associated with these attributes. However, the limitation of this study is due to the fact that its sample size is appropriate for this type of qualitative study but does not allow us to make general inferences to conclude that newly found shopping attributes are relevant for the entire population. For future study, the output of this work can be used to guide the development of framework and questionnaires to use in the subsequent quantitative study to confirm the importance of these attributes. It could then be used as guidance to develop a tool that helps shoppers evaluate the live streams based on the relevant attributes that match their shopping values.

\section{References}

Aghekyan-Simonian, M., Forsythe, S., Suk Kwon, W., \& Chattaraman, V. (2012). The role of product brand image and online store image on perceived risks and online purchase intentions for apparel. Journal of Retailing and Consumer Services, 19(3), 325-331. doi:https://doi.org/10.1016/j.jretconser.2012.03.006

Borgardt, E. (2020). Means-End Chain theory: a critical review of literature. Prace Naukowe Uniwersytetu Ekonomicznego we Wrocławiu, 64, 141-160. doi:10.15611/pn.2020.3.12

Brynjolfsson, E., \& Smith, M. D. (2000). Frictionless Commerce? A Comparison of Internet and Conventional Retailers. Management Science, 46(4), 563-585. Retrieved from https://EconPapers.repec.org/RePEc:inm:ormnsc:v:46:y:2000:i:4:p:563-585

Cai, J., Wohn, D. Y., Mittal, A., \& Sureshbabu, D. (2018). Utilitarian and Hedonic Motivations for Live Streaming Shopping. Paper presented at the Proceedings of the 2018 ACM International Conference on Interactive Experiences for TV and Online Video, SEOUL, Republic of Korea. doi:https://doi.org/10.1145/3210825.3210837

Crosby, L. A., Evans, K. R., \& Cowles, D. (1990). Relationship Quality in Services Selling: An Interpersonal Influence Perspective. Journal of Marketing, 54(3), 68-81. doi: $10.2307 / 1251817$ 
Davari, A., Iyer, P., \& Rokonuzzaman, M. (2016). Identifying the determinants of online retail patronage: A perceived-risk perspective. Journal of Retailing and Consumer Services, 33, 186-193. doi:https://doi.org/10.1016/j.jretconser.2016.08.009

Electronic Transactions Development Agency (2020, January). Thailand Internet User Behavior 2019 (Retrieved from) https://www.etda.or.th/th/UsefulResource/publications/Thailand-Internet-User-Behavior-2019_Th.aspx

Hou, F., Guan, Z., Li, B., \& Chong Alain Yee, L. (2019). Factors influencing people's continuous watching intention and consumption intention in live streaming: Evidence from China. Internet Research, 30(1), 141-163. doi:10.1108/INTR-04-2018-0177

Johnson, K. K. P., Kim, H.-Y., Mun, J. M., \& Lee, J. Y. (2015). Keeping customers shopping in stores: interrelationships among store attributes, shopping enjoyment, and place attachment. The International Review of Retail, Distribution and Consumer Research, 25(1), 20-34. doi:10.1080/09593969.2014.927785

Ladhari, R., Gonthier, J., \& Lajante, M. (2019). Generation Y and online fashion shopping: Orientations and profiles. Journal of Retailing and Consumer Services, 48, 113-121. doi:https://doi.org/10.1016/j.jretconser.2019.02.003

Leeraphong, A., \& Sukrat, S. (2018). How Facebook Live Urge SNS Users to Buy Impulsively on $\mathrm{C} 2 \mathrm{C}$ Social Commerce? Paper presented at the Proceedings of the 2nd International Conference on E-Society, E-Education and E-Technology, Taipei, Taiwan. https://doi.org/10.1145/3268808.3268830

McGoldrick, P. (2002), Retail Marketing, 2nd ed., McGraw-Hill, Maidenhead.

McKnight, D. H., \& Chervany, N. L. (2001). What Trust Means in E-Commerce Customer Relationships: An Interdisciplinary Conceptual Typology. International Journal of Electronic Commerce, 6(2), 35-59. doi:10.1080/10864415.2001.11044235

Reynolds, T. J., \& Gutman, J. (1988). Laddering theory, method, analysis, and interpretation. Journal of Advertising Research, 28(1), 11-31.

Sebald, A. K., \& Jacob, F. (2019). What help do you need for your fashion shopping? A typology of curated fashion shoppers based on shopping motivations. European Management Journal. doi:https://doi.org/10.1016/j.emj.2019.08.006

Shankar, V., Inman, J. J., Mantrala, M., Kelley, E., \& Rizley, R. (2011). Innovations in Shopper Marketing: Current Insights and Future Research Issues. Journal of Retailing, 87, S29-S42. doi:https://doi.org/10.1016/j.jretai.2011.04.007

Sun, Y., Shao, X., Li, X., Guo, Y., \& Nie, K. (2019). How live streaming influences purchase intentions in social commerce: An IT affordance perspective. Electronic Commerce Research and Applications, 37, 100886. doi:https://doi.org/10.1016/j.elerap.2019.100886

Wagner, T. (2007). Shopping motivation revised: a means- end chain analytical perspective. International Journal of Retail \& Distribution Management, 35(7), 569-582. https://doi.org/10.1108/09590550710755949 
Wongkitrungrueng, A., \& Assarut, N. (2018). The role of live streaming in building consumer trust and engagement with social commerce sellers. Journal of Business Research. doi:https://doi.org/10.1016/j.jbusres.2018.08.032

Wongkitrungrueng, A., Dehouche, N., \& Assarut, N. (2020). Live streaming commerce from the sellers' perspective: implications for online relationship marketing. Journal of Marketing Management, 36(5-6), 488-518. doi:10.1080/0267257X.2020.1748895 